\title{
The links between structural and social marginalisation - social relations of young Finnish adults not in employment or education
}

\author{
Author details: \\ Vesa Välimäki (corresponding author) \\ vesa.valimaki@tuni.fi \\ ORCID: 0000-0001-8537-9686 \\ Tampere University, Faculty of Social Sciences, 33014, Tampere, Finland \\ Antti Kivijärvi \\ ORCID: 0000-0003-3931-4069 \\ University of Helsinki, Faculty of Social Sciences, 00014, Helsinki, Finland
}

Sanna Aaltonen

ORCID: 0000-0002-3977-8245

University of Eastern Finland, Department of Social Sciences, 70211, Kuopio, Finland

\section{Funding details:}

The research was funded by the Strategic Research Council at the Academy of Finland, grant no. $\underline{303615 / 303650}$.

This is an Accepted Manuscript of an article published by Taylor \& Francis in Journal of Youth Studies on 14.10.2019, available

online: http://www.tandfonline.com/10.1080/13676261.2019.1676884

\begin{abstract}
This paper focuses on the social attachments and detachments of 16- to 29-year-old young adults who are not in employment or education, and consequently not part of the sociability related to work or school. While the characteristics of this group tend to be well documented, there is less empirical research on their social relations. Here, the aim is to explore the interlinkages between young adults' structural and social marginalisation through an analysis that draws upon two types of interlinked datasets: follow-up surveys and online group discussions conducted among a sample of young adults recruited from targeted youth services during 2017-2018. Leaning on empirical evidence, the paper argues that structural marginalisation is associated with the social marginalisation of young adults. With the use of both quantitative and qualitative data, the paper provides new youth-specific insights into the arguments made in the previous literature on financial constraints and stigma as mechanisms between structural and social marginalisation.
\end{abstract}

Keywords: loneliness, structural marginalisation, social marginalisation, targeted youth work, mixed methods 


\section{Introduction}

Social relations, and peer relations in particular, are widely studied topics in youth research and have been identified as a vital part of youth wellbeing (e.g. Cotterell 1996; Myllyniemi 2012). Key transitions related to education and work are influenced and supported by peers, but equally affected by the lack of peer relations. While making transitions opens up opportunities for establishing new friendship circles, transitions are also associated with losing connections and the risk of social exclusion (Bynner \& Parsons 2002; Miller et al. 2015; Rönkä 2017). However, the lack of peer relations and resultant loneliness among young adults who have fractured transitions, a group often denoted as NEETs (not in employment, education or training), has attracted little attention in research literature. The NEET label highlights an inactive and non-standard position in relation to paid work and formal education, and diverts attention away from social relations, despite the fact that having social support while outside of education and work is seen as vital for the mental health of young adults (Kieselbach 2003; Popp \& Schels 2008; Milner et al. 2016). Social networks are also seen as an important factor in the re-employment of the unemployed (Granovetter 1977; Kunze \& Suppa 2017, 215-216).

In this article we focus on the social relations and loneliness of 16- to 29 -year-old young adults ${ }^{1}$ who, for various reasons, lack structural attachments to society in the form of a status as a student or an employee. Consequently, our aim is to trace the interlinkages between structural and social marginalisation. Structural marginalisation denotes at least temporary exclusion from educational institutions or the labour market. The notion of social marginalisation refers to both the lack of and dissatisfaction with social relations. As previous studies have rightly concluded, not all young adults outside education and the labour market suffer from social marginalisation, and they may have a large network of friends, family members and relatives (Levitas 1996; Hammer 2003; Heikkinen 2000). Moreover, for young adults, structural marginalisation may not be as detrimental to their social relations as it is for older peers as their employment history is limited (Grimmer 2016; Chabanet et al. 2016).

Despite the remarks above, young adults not in employment or education have been found to report more loneliness than their working or studying peers (Gretschel \& Myllyniemi 2017). Overall, unemployment has been found to be associated with higher levels of loneliness than average (Peplau \& Perlman 1982; Moisio \& Rämö 2007). Further, previous studies have demonstrated how during unemployment individuals tend to have lower levels of social participation, and withdraw from public activities into private relationships (Dieckhoff \& Gash 2015; Kunze \& Suppa 2017).

In order to study the interlinkages between structural and social marginalisation, we adopted a mixed methods approach and based our analysis on two interlinked datasets gathered through targeted youth work in three Finnish cities: baseline and follow-up survey data, and digital group discussions conducted among a sample of young adults $(n=147)$ during 2017-2018. In Finland,

\footnotetext{
${ }^{1}$ The Finnish Youth Act defines all those under the age of 30 as young people.
} 
unlike in many other European countries, organising youth work is the responsibility of municipalities and provided by professional youth workers. According to the current practice, Finnish youth workers are expected to contact and offer their services to all young people not engaged in educational institutes and the labour market. ${ }^{2}$

The wider context for the article stems from interest in one of the most pressing societal concerns: even though unemployment and dropping out of the education system have become persistent structural conditions, labour market participation and educational attainment are still seen as prime indicators of societal integration. Consequently, it is important to ask how not being in education and employment is reflected in maintaining, losing or creating social relations, and how social relations are experienced in the context of structural marginalisation.

\section{Structural and social marginalisation}

The argument advanced in this article rests on the sociological perspective of friendship. Some of the previous and particularly late-modernist theorists have put strong emphasis on friendship as a voluntary act disembedded from traditional attachments, while at the same time neglecting the existing structural constraints (see Chambers 2006). As argued by Allan (1998), friendships should be seen as socially patterned. Friendship formation is not just a personal act, an outcome of one's choices, but also constrained by structural forces that range from social class to gender and ethnicity, but also to social opportunities at the micro level such as proximity and perceived similarity (see e.g. Crosnoe 2000; MacDonald \& Shildrick 2007; Kivijärvi 2014).

These sociological approaches towards friendships, which underline the importance of structural conditions, led us to focus on the constraints that young adults not in employment or education might face in their sociability. As they are excluded from the sociability related to work and education, they may have few opportunities to form friendships (Emler \& McNamara 1996, 136). In line with the above arguments, we review the key findings of previous research on the links between structural and social marginalisation. In the previous literature (for similar summaries, see Dieckhoff \& Gash 2015; Lahusen \& Giugni 2016), these interlinkages have been explored mainly in the context of unemployment, and explained by two mediating mechanisms: financial constraints and stigma.

The link between reduced social participation and financial constraints during unemployment has been empirically validated in many studies (e.g. Gallie et al. 2003; Dieckhoff \& Gash 2015). For young adults, a poor financial situation can be even more detrimental to their well-being than their employment status as such because, unlike their older peers, young adults have not experienced long periods of working routine (Grimmer 2016). The unemployment of young adults does not always imply a loss of existing work-related social contacts, but it does point to limited financial resources. As young adults' leisure activities have become more commercialised (Furlong \&

\footnotetext{
${ }^{2}$ According to the Finnish Youth Act (1285/2016), various authorities are required to report those young people who have dropped out of the education system or military service to local youth departments. In addition, young people who are unemployed or who are a cause for concern in some other ways might also be reported.
} 
Cartmel 2007, 11), financial constraints can have a negative effect on young unemployed people's ability to participate in social activities (ibid. 80; Damelang \& Kloß 2013).

The financial resources of structurally marginalised young adults in Finland often consist of state provided benefits, which might be supplemented by parental support. Within Europe, the financial resources needed for social participation differ depending on the different welfare regimes (Hammer 2003), with the social-democratic welfare model in the Nordic countries often defined as more effective in counteracting the negative financial consequences of unemployment (Julkunen 2002; see also Heikkinen 2000). However, even though the minimum standard of living is often reached, low income levels and relative poverty can be problematic when it comes to sociability (Hammer \& Julkunen 2003). According to the Finnish Youth Barometer (Myllyniemi \& Kiilakoski, 2017, 99-100), the most dissatisfied with their social relationships were the unemployed and young adults who experienced financial constraints regarding their hobbies.

In addition to financial constraints, the stigma of unemployment, being ashamed of one's status, has been used as an explanation for the lower social participation rates of the unemployed as a result of deliberately avoiding public sociability and resorting to more private relationships (e.g. Monticelli et al. 2016). This explanation has gathered more ambivalent interpretations, and empirical evidence has been less unequivocal (see Dieckhoff \& Gash 2015). However, the stigma of unemployment is seen as an important explanation in a number of qualitative studies (see Lahusen \& Giugni 2016). Drawing upon Goffman's terminology (1963, 2-3), the stigma of structural marginality is related to a character failing. Since the status of an unemployed person is not immediately apparent and can therefore be concealed, the individual is discreditable in Goffmanian terms (ibid. 41-42).

For structurally marginalised young adults, the stigma may affect everyday interactions with peers who are either students or employed, namely their out-group (Goffman 1963, 12). While being employed and earning an income from work is commonly seen as playing a legitimate social role (Rantakeisu et al. 1999), there are cultural and temporal differences associated with the stigma of unemployment. Bergqvist (2016) argues that in Sweden, a country with an allegedly strong work ethic, being unemployed is often associated with not being able to live by the societal norms, and it can duly lead to avoiding social situations. Depending on the societal discourse and general understanding of the root causes of unemployment, the unemployed may reproach themselves for being out of work and attribute their situation to personal failings (Dieckhoff \& Gash 2015).

However, the stigma of unemployment may decrease as a result of the high levels of youth unemployment and increased precariousness of working life that have characterised Europe during the economic downturn (Chabanet et al. 2016; see Heikkinen 2000 on the recession in the 1990s). Further, not just unemployment but other kinds of circumstances differing from the normative life course of young adults may contribute to experiences of loneliness. For young adults, status as a student is often the most expected and accepted. With their nationally representative survey data, Luhmann \& Hawkley $(2016,31)$ demonstrated that levels of loneliness were relatively high both for young adults without jobs and those who were working full-time, but not among students working part-time. In our analysis, we will test the above hypotheses from both quantitative and qualitative perspectives. 


\section{Data and methods}

This study is part of a consortium project entitled 'Inclusive Promotion of Health and Wellbeing, PROMEQ' funded by the Strategic Research Council (SRC) of the Academy of Finland (303615/303650) and aimed at developing engaging models of promotion of wellbeing for underprivileged groups in Finland. ${ }^{3}$

Within the subproject focusing on young adults not in employment or education, the researchers collaborated with targeted youth services such as outreach youth work, one-stop guidance centres, and youth workshops in the cities of Jyväskylä (Central Finland), Kouvola (Southeast Finland) and Vantaa (Southern Finland, metropolitan area). The professionals in targeted youth services were asked to help in recruiting young adults who were both clients of these services and not in employment or education at that time. Some of those recruited had a longer history of being structurally marginalised, but there were also those who could be understood as being between studies or jobs. Baseline interviews with the young adults were conducted and followed by an intervention consisting of nine weeks of online group discussions moderated by the youth workers. The last phase included follow-up interviews conducted approximately six months after the initial round. These different field work ${ }^{4}$ approaches yielded empirical data for the study in the following manner.

The first dataset consists of responses to a two-phase survey comprising mainly quantitative items on living conditions, subjective wellbeing, social relations, living habits and service use. The baseline survey $(n=147)$ was conducted in two waves during spring and autumn 2017 in the presence of a researcher whose task was to offer help if needed and to initiate discussions on the themes included in the survey (for a description of the respondents, see Table 1). Forty-four interviews were recorded and transcribed with the permission of the informants, while notes were made on the remainder and the ensuing qualitative data was used to complement the survey data. The interviews lasted from 20 minutes up to one and a half hours. Approximately six months after the baseline interview, a follow-up questionnaire $(n=107)$ was sent to respondents either as a digital link or via regular mail, including the same questions as the baseline survey. Males and those who did not participate in the online groups tended to drop out of the follow-up phase.

Table 1. Description of the respondents $(n=147)$

In this article we used the baseline survey to investigate the association and mediators between social and structural marginalisation. The follow-up survey enabled us to scrutinise structural marginalisation as a predictor of social marginalisation. To do this, we utilised mostly continuous variables on social life, societal statuses, financial situation and stigma. Social life was measured with variables on frequency of contacts with friends and relatives (daily/weekly/monthly/less often), participation in structured and unstructured group activities (often/sometimes/never), the frequency

\footnotetext{
3 The research was approved by the University of Eastern Finland Ethics Committee.

${ }^{4}$ The fieldwork was conducted by Sanna Aaltonen, Antti Kivijärvi and Martta Myllylä.
} 
of feeling lonely (constantly/often/sometimes/rarely/never), and experiencing social and emotional loneliness. Social loneliness refers to the lack of peer company, while emotional loneliness denotes the absence of close friends with whom to share one's life (Weiss 1973). Both were measured using the UCLA12 loneliness scale (see Russell 1996).

Societal status was transformed into one survey question on the respondents' current position (student/employed/unemployed/in activation measures or rehabilitation/sickness allowance or temporary disability pension/family leave/other). Financial situation was measured by asking about current situation and the situation during childhood. The former was probed with two sets of questions. First, respondents were asked whether it was easy to cover their expenses with their current income (six-point scale from very easy to very difficult). Second, respondents faced a set of questions on daily financial problems such as not being able to afford food and having to skip leisure activities or paying housing expenses (yes/no). As for the financial situation during childhood, respondents were asked to estimate their families' living standard on a scale from one to ten. Finally, stigma was measured by combining two five-scale (from fully agree to fully disagree) items: 1) I feel that other people have no appreciation of what I do, and 2) Some people look at me with disdain because of my employment status or income level. In addition to descriptive methods and statistical tests, quantitative datasets were scrutinised with linear regression analyses.

The second dataset drawn upon here consists of the anonymous digital group discussions conducted during 2017-2018 in four groups. The groups were composed of 8-14 young adults, 41 in total, recruited from among the baseline survey respondents, and at least two youth workers who acted as moderators. Group participants, particularly those who were active discussants, were more likely to suffer from loneliness and poor wellbeing in general. Those who participated probably felt a greater need for this type of activity. It can therefore be expected that this dataset enables a more in-depth investigation into the affiliations between structural and social marginalisation. The group discussions lasted nine weeks and the moderators introduced a new theme each week. The comments made by the young participants were for the most part prompted by the moderators and their introductions and questions.

In the analysis, the online comments were interpreted in terms of the accounts that participants provided to make their experiences and thoughts understood to the moderators and to fellow participants, as well as to themselves (Coffey \& Atkinson 1996). Overall, the discussion threads included 338 posts of differing lengths submitted by the young adults. The discussions were thematically coded using ATLAS.ti qualitative software. For this article, we used interpretive reading to analyse the parts where participants depicted their social relations and constraints on sociability as well as experiences of loneliness. Our analysis was theory-oriented as we focused on 1) how financial constraints and 2) how the stigma of being structurally marginalised were used as an explanation for social marginalisation. However, as seen in our results, the stigma of being structurally marginalised was not mentioned as an explanation for social detachment. As we searched for alternative explanations in the data, we used a more data-driven approach to see how the participants described sociability and loneliness. 
Both datasets were analysed individually. However, the analysis of each was informed not only by conceptualisations made in the previous literature but by each other, and the focus of the analysis was defined along with the writing process. All of the written material was read and reflected on collectively by all of the authors, but the statistical analysis was conducted by Antti Kivijärvi. The mixed methods approach in which we combined data, methodologies and researcher observations facilitated a more comprehensive understanding of the scope and structures of social relations compared to an approach relying on one type of data only (see Rönkä 2017).

Finally, it is important to emphasise the distinct nature of our data. Since we are dealing with a nonprobability sample, the results cannot be generalised to all structurally marginalised young adults in Finland, but have to be treated as broad and tentative. We resorted to this strategy due to the fact that structurally marginalised young adults are a hard-to-reach group for research purposes and more robust sampling methods were not applicable. According to the official statistics, the youth services we used as recruiting channels had over 5,566 clients or visits during 2017. This figure included repeat visits by some young adults, and some individuals with whom contact had been tenuous (e.g. one phone call or a brief encounter). Consequently, we were not able to determine the exact quantity and quality of our sphere of activity. In the case of the outreach work, professionals operated as gatekeepers between us and the young adults, recruiting only some of them (see Aaltonen \& Kivijärvi 2018). In the youth workshops and in the one-stop guidance centres, we were able to offer all of the young adults we met while conducting the field work the opportunity to participate. A majority accepted the invitation. In this way, we reached those who were at least to some extent attached to the youth services and probably not experiencing acute and severe problems with intoxicants or their mental health.

\section{The interlinks between social and structural marginalisation in the survey data}

Descriptive analyses of the baseline data provided few surprises: there was quite a strong association between structural and social marginalisation. Feelings of loneliness were fairly frequent among the respondents. One-third reported feeling lonely constantly or often. Depending on the comparison data and the way they were generated, this figure is three to ten times greater compared to people of the same age in Finland in general. ${ }^{5}$

In spite of the prevalence of loneliness, it is worth pointing out that two-thirds of the respondents reported feeling lonely only sometimes or less frequently. Moreover, estimating the level of loneliness occasionally included hesitation, and some did not wish to portray themselves as lonely persons.

For the most part, Ifeel lonely. I would say rarely. No, often. Sometimes. (Interview)

\footnotetext{
5 ATH (Adults' health and wellbeing) and HYPA (Wellbeing and services) surveys are conducted by the National Institute of Health and Wellbeing. ATH is a postal survey which covered 8,769 young adult respondents in 2013. HYPA is based on phone interviews, reaching 575 young adult respondents in 2013. In ATH, 11.3\% reported feeling lonely often or constantly, while the corresponding figure was $2.9 \%$ in the HYPA survey. The frequencies have not fluctuated to any significant extent from year to year.
} 
Furthermore, the respondents were not socially isolated. The differences between them and the national averages in terms of social contacts and leisure participation were either small or ambiguous. The majority of the respondents reported being in contact with their friends (87.6\%) and mothers (76.2\%), and approximately half with their fathers (47.6\%), on a weekly basis at least. Five years earlier, the corresponding figures in the nationally representative Youth Barometer were $92.5 \%, 50 \%$ and $41 \%$ for people of the same age (Myllyniemi 2012, 36). Hence, there were only marginally fewer contacts with friends among the respondents, but relationships with mothers seemed intense. Arguably, their structural marginalisation 'activates' intergenerational interdependence and care.

What many of the respondents seemed to lack was not primarily close emotional bonds but a wider group of friends with whom to spend time and participate in social activities. This might indicate a missing peer group often formed through work and particularly student communities. In the baseline data, on a scale from one to four in which large scores illustrate high loneliness, the mean value for social loneliness was 2.17, while for emotional loneliness it was 1.92 (see also Kivijärvi et al. 2019). During our discussions, the interviewees described their lack of peer networks in the following ways:

The interviewee stated that he has a couple of friends, but not a wider group of people. (Field notes)

[Reads the statement in the questionnaire aloud] 'I feel that I am a part of a group of friends.' What group? I have, like, two real friends. (Interview)

In order to study the factors that might explain the association between structural and social marginalisation, linear regression analyses using the baseline data were performed (see Table 2). The primary aim of the analyses was to test the hypothesis derived from the literature, namely whether the association could be explained by financial difficulties and stigma. At the time of the baseline survey none of the respondents were in employment or education. Social marginalisation was operationalised as a self-reported and three-fold notion of loneliness. In the three regression models it can be observed that frequency of loneliness and social and emotional loneliness show more or less the same results.

Table 2: Determinants of loneliness in the baseline survey $(n=147)$, linear regression models

The models show many expected and some unexpected results. Loneliness was strongly related to shortcomings in peer sociability, which cannot be replaced with parental connectedness or even with romantic partnerships. Unlike contacts with parents and to some extent intimate relationships, contacts with friends and participation in unstructured group activities were strongly associated with various forms of loneliness. Thus, loneliness and isolation from informal peer sociability in particular were bound together. ${ }^{6}$ Background variables such as age and gender did not play a role in the models.

\footnotetext{
${ }^{6}$ It is worth noting that participation in structured leisure activities (organised e.g. by civil society organisations) was not associated with loneliness in the regression models. Moreover, in the baseline survey the percentage of those
} 
Furthermore, and in line with some of the previous literature, stigma was associated with all three forms of loneliness. Together with contact with friends, the stigma of structural exclusion was the strongest independent variable explaining loneliness. Thus, the survey data reinforces the previously ambivalent result on stigma as a mediating factor between structural and social marginalisation. The stigmatising power of marginal societal status was also manifested during the baseline interviews: Contrary to their 'objective' statuses outside education or employment, quite a few chose to classify themselves as students $(n=19)$ or employees $(n=5)$. The student identity might be the most attractive for young adults when presenting themselves in everyday life and more marginal statuses might cause withdrawal from sociability.

The unexpected results are related to financial difficulties explaining the association between structural and social marginalisation. In the regression models, current monetary problems were not associated with loneliness. It is possible that a Nordic welfare state such as Finland can provide leisure opportunities also for those not in employment or education through financial benefits and subsidised service provision. However, it seems that the association between loneliness and financial difficulties might have more far-reaching roots. Self-reported childhood poverty was strongly or moderately associated with both frequency of loneliness and social loneliness in the first and second models, but not statistically significantly in the final and adjusted models. It might be that for some respondents the ability to participate in often commercial peer leisure has been limited for a long time. Moreover, many were probably still financially dependent on their parents, and their income level may have been reflected in the survey responses.

Lastly, with the help of the follow-up data, it was possible to analyse the issue of change and whether structural marginalisation predicts social marginalisation. A slight increase occurred in all forms of measured loneliness between the baseline and follow-up surveys. However, in the t-tests this increase was statistically significant only in the case of emotional loneliness. ${ }^{7}$ Changes in social contacts were also modest. Parallel with the change in the levels of loneliness, a decrease in the frequency of contacts was more often the case than an increase.

In the context of this article, it is of paramount importance to look into the changes in societal statuses. Status changes can be quite rapid during young adulthood and this might influence social marginalisation as well. Out of those who responded to the follow-up survey, less than half (47.2\%) reported the same societal status. A quarter (24.5\%) reported having been employed, or enrolled in education. Approximately $10 \%$ had been enrolled in activation measures, and slightly less than $20 \%$ reported some other change in their status (e.g. parental leave, temporary disability pension or military service).

\footnotetext{
participating in structured activities was similar to the percentages in the nationally representative ATH and HYPA surveys in 2013. Consequently, structured leisure activity may not be the key issue in breaking the bond between structural and social marginalisation.

${ }^{7}$ The increase may be explained at least in part by the change of surveying method between baseline and follow-up phases. It might be easier to report negative and personal matters in postal or e-questionnaires than in the presence of a researcher.
} 
According to the descriptive analyses (one-way ANOVAs), being employed and participating in education or activation measures were associated with reduced feelings of loneliness. The differences were rather small and statistically significant only in the case of frequency of loneliness (see Figure 1). However, due to the small sample size, it might still be that even activation measures have positive consequences other than maintaining workability and satisfying employment officials.

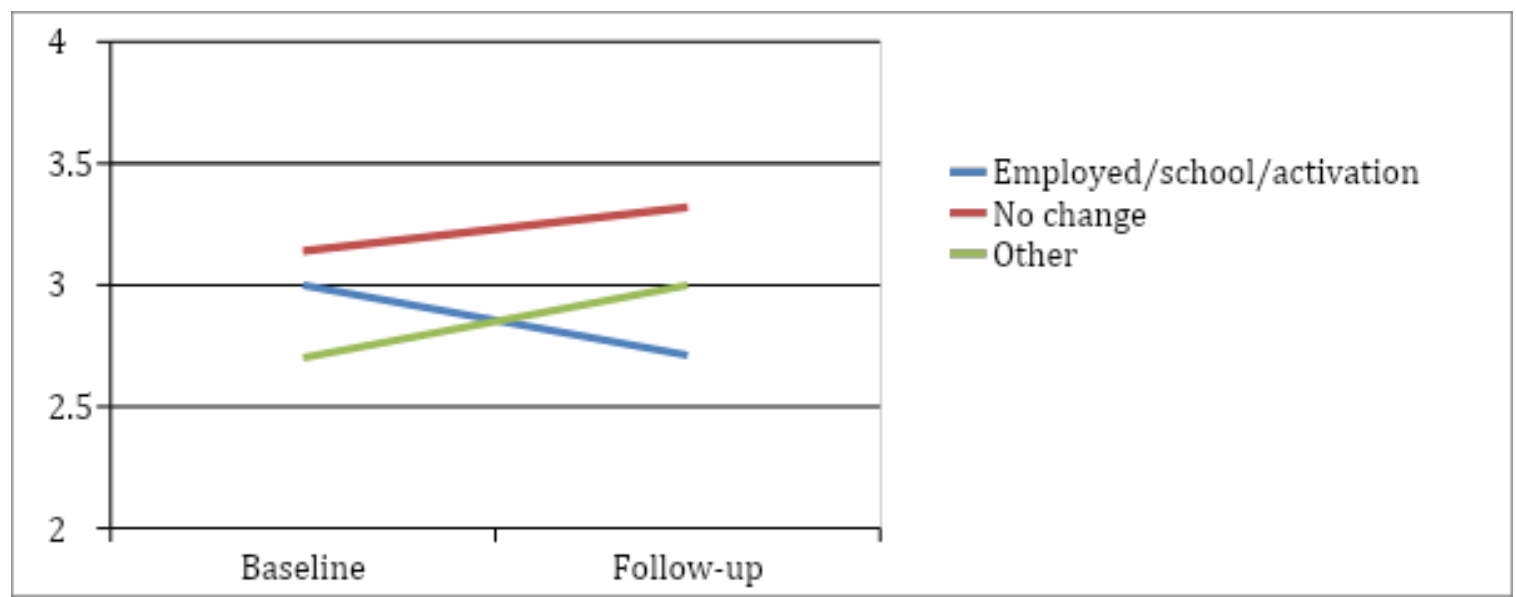

Figure 1. Change in the frequency of loneliness on a five-point scale according to the change in societal status

When looking descriptively (one-way ANOVAs, not shown) at the alleged mediating variables between structural and social marginalisation, a change in stigma was associated with changes in societal statuses, while changes in financial difficulties were not. Quite surprisingly, even being employed did not improve the self-reported financial situation. Precariousness in the form of temporary contracts, low salaries, internships or public pay subsidies might explain the result. On the other hand, being employed and enrolment in education clearly reduced the experienced stigma, but this was not the case with participation in activation measures.

In more robust linear regression models (Table 3), access to employment, education and activation measures (independent variable 'societal status') had only weak associations with reduced loneliness. Notable in the models is, again, the strong role of decreased stigma as a predictor of decreased loneliness. This applied particularly to frequency of loneliness and social loneliness. Other statistically significant predictors in one of the final models were relationship status and, quite surprisingly, contact with a father. Increased contact with a father and either a newly established romantic relationship or an enduring one predicted a decrease in the frequency of loneliness. These findings - albeit not systematically observed - challenge the basic result of the strong association between loneliness and peer relations. 
Table 3. Predictors of change in the levels of loneliness between baseline and follow-up surveys $(\mathrm{n}=107)$, linear regression models

To conclude the quantitative analysis, there appears to be a complex interrelationship between structural and social marginalisation. Structural marginalisation of young adults is associated with and probably even causes social detachments. However, the assumed causal relation seems to be mediated by several factors, most clearly by stigma but perhaps also by financial support or other interventions by parents and public institutions.

\section{Sociability and loneliness in the digital group discussions}

To gain a better understanding of the young adults' perceptions of social relations and loneliness in relation to financial difficulties and stigma, we now turn to the online group discussions. While the discussion threads were predominantly initiated by the adult moderators, the forum allowed the young adults to further exemplify and clarify their understanding of social relations in writing.

Starting with financial issues, the most common sources of income among the digital group participants were supplementary benefits from the state such as basic social assistance or housing allowance, both of which can be applied for online from the Social Insurance Institution of Finland. In line with the quantitative findings, parents were often mentioned as providing a helping hand in cases where money ran out before receiving the benefits. In the discussion thread on financial situation and living conditions, an exchange occurred about tight finances and being frugal.

I get by mainly on housing and unemployment allowances. It's enough for necessities but lately I haven't been able to make any bigger purchases. I used to have savings, but I dipped into them to pay my living costs when the allowances were not enough.

Partly in contrast to the quantitative findings, current financial constraints were recognised as an explanation for social detachments. Mention was made of how difficult it was to maintain friendships in cases where friends lived far away, and it was too expensive to use public transport. Social gatherings were sometimes deemed too difficult to take part in because they often required financial resources. This should be seen in the light of previous studies highlighting unemployed young people's inability to participate in commercial activities due to a lack of resources (Furlong \& Cartmel, 2007, 80).

This year, because of problems with Kela (Social Insurance Institution of Finland), I haven't seen my friends very often. None of my friends live in the same area as me so we like to meet in [a city nearby]. Even getting there costs money. Not to mention if you spend the whole day in the city and need to eat something as well.

The lack of financial resources was seen as an obstacle in forming new relationships. This was highlighted when the participants were asked about their current hobbies and interests. Our analysis reveals that some of the low-cost hobbies that respondents engaged in were solitary pursuits such as 
reading, jogging or listening to music, but social group activities that usually include an entrance or membership fee were rarely mentioned. Respondents often shared their interest in group activities such as horse-riding or team sports in the online discussions, but cited their lack of financial resources as one of the reasons for not pursuing them.

At the moment I don't have any hobbies simply because money is so tight.

The stigma of being structurally marginalised that came up in the quantitative analysis was not mentioned as an explanation for social detachment; the young adults in our online groups did not attribute their withdrawal from social relationships to feelings of being ashamed about their societal status. Obviously, this could be because they were not encouraged to write about stigma or feeling ashamed of their status in the same way that they were about their feelings of loneliness. However, nor were the participants asked about whether they regarded financial difficulties as impeding their ability to participate socially. It could also be that the online discussants did not necessarily see the stigma of structural marginalisation as shameful, as could be interpreted from the quantitative analysis. Following this line of thought, unemployment or dropping out of education can be considered unfortunate, but rather than being a destiny, it remains fixable during young adulthood.

While the lack of stigma regarding structural marginalisation was not explicitly discussed, the stigma of being socially marginalised was evidenced in the online threads. This was particularly the case in discussions where the participants shared their own experiences of loneliness. The message quoted below appeared after two other young adults explained how they had experienced loneliness previously but not anymore.

Somehow I feel 'embarrassed' to admit that from time to time I feel rather lonely, although I have some close friends. Still, I know that there are many people who don't have anybody and so it feels wrong to speak or feel like this. OI'm no good at making new friends and I feel like an outsider, especially in a bigger crowd, which makes things even more complicated.

It may be the case that during youth and young adulthood, the stigma of being excluded from peer sociability is even stronger in the case of structurally marginalised young adults. In contrast to current structural marginalisation, loneliness might have represented another kind of stigma, more personal, more difficult to fix and possibly long-lived. Young people are expected to live a socially full life with numerous friends while detaching themselves from their parents, but not yet committing to or establishing their own families. During this phase of expected peer sociability, an ambivalent status related to the labour market, and particularly the education system, might reinforce the idea of having a status as socially excluded.

Even though there were several disclosures about loneliness in the online threads, many discussants detached their current selves from loneliness. This was done by talking about past experiences of loneliness, or by taking an analytical stance towards the affliction. The latter involved contemplating the general reasons for loneliness. Moreover, some discussants quite explicitly 
detached themselves from loneliness by trying to find solutions to other peoples' loneliness or by encouraging them: "Those of you who feel lonely, be brave!".

While the anonymity of the digital group allowed some of the participants to disclose the stigma of loneliness and isolation, the stigma of being structurally marginalised remained hidden. Even though financial difficulties were mentioned as an obstacle to sociability, most of the young adults explained their loneliness by resorting to psychological discourse (Illouz 2008). Many wrote about their negative experiences in social situations such as painful incidents of bullying in the past, feelings of lacking valued personal traits such as good social skills, and having problems with mental issues such as anxiety and depression. As with the financial constraints, these barriers were seen as restricting one's ability to participate in social gatherings.

I have problems making and maintaining social contacts. For the past few years, I've been diagnosed with a fear of social situations and I'm about to see the psychiatrist to get rediagnosed. My therapist suspects that I may have an inhibited personality disorder (and possible ADD). I was also bullied in elementary school. In my case, the reason was a slightly distinct tone of voice and singing voice. Being exposed to bullying had a big impact on my self-confidence, social interaction and even on music as my hobby. I suffered from recurring depression for years and had to drop out of vocational school because of these problems.

The psychological dimension was brought up again in the discussion on recreation. Some of the young adults explained that they were unable to take up a new hobby because of a lack of motivation, or due to laziness or passiveness. Other than problems with motivation, the barriers were posed by experiences of social anxiety and low self-esteem.

I'm rather lonely and I've been diagnosed with an inhibited personality disorder. All social events are difficult for me because of tensions and feelings of inadequacy. Over the course of time, keeping my mouth shut has become a habit, and making any kind of contact demands effort.

This finding supports the therapeutic narrative argument (e.g. Silva 2012) - rather than trying to find structural explanations, young adults turn to themselves and their psyche. This might partly explain why social marginalisation appears to be difficult to tackle with external interventions. Our aim here is not to downplay the significance of mental issues. Gaining access to the appropriate services and medical treatment is often dependent on a medical diagnosis. Further, as the psychologically-oriented literature has rightly cautioned, thrusting people suffering from different anxieties and social inhibitions into the middle of vivacious peer sociability might have harmful effects, while making the sufferer's problems even more apparent (e.g. Lagus \& Honkela 2016, 281). However, from a sociological perspective, it seems that many of the young adults have adopted psychological and individualistic discourses that are highly influential today in many societies (Illouz 2008). Structural or social conditions - despite the societal position of the 
discussants - seemed to be of lesser significance, or at least remained less clear-cut for them (see also Husu \& Välimäki 2017; Silva 2013).

\section{Conclusion}

In this article we have explored the interlinkages between young adults' structural and social marginalisation and scrutinised the significance of the two mediating factors identified in the literature: financial constraints and stigma. Our first finding is in line with the previous research, indicating that structural marginalisation is associated with and probably even causes social marginalisation to some extent. Structural marginalisation seems to increase the risk of being excluded from peer sociability, while at the same time activating the caring relationships with parents, particularly with mothers.

Our second finding concerning the mediating role of financial difficulties and stigma is more ambiguous. Analysis of the qualitative data in particular confirmed that financial constraints explain the connection between structural and social marginalisation. However, in the quantitative data, current deprivation was less significant than intergenerational poverty embedded in family histories. When it comes to stigma, the quantitative and qualitative datasets seem to provide conflicting results. Even though the stigma proved to be a strong mediating variable between young adults' marginal status and loneliness in the survey data, this did not come up in the online discussions.

The most obvious explanation for the above discrepancies concerns the different methodological approaches. In the questionnaires, the 'audience' were adult researchers and perhaps 'generalised others', with their possible disregard towards the respondents who had failed to meet the normative criteria of being an employee or a student. In other words, the young adults were probably not immune to the moralising and devaluing discourse over NEETs, which might have been reflected in their responses as well. Conversely, the digital group discussions were more peer and 'in-group' oriented (Goffman 1963, 112-113). Since not being in employment and education was a status shared by the majority of the discussants, the stigma of structural marginalisation may have been irrelevant while more concrete issues related to their daily life such as finances and current poverty were brought up quite frequently.

Furthermore, it is possible that the observed significance of stigma in the survey data is manifested as a strong tendency to draw upon psychological discourse in the group discussions. It might be that, in addition to shame towards one's status, the stigma operationalised in the questionnaire functions as an indicator of various anxieties, poor self-respect and self-devaluation. All of these features were frequently mentioned as both causes of and reasons for loneliness in the research literature (e.g. Hall-Lande et al. 2007; Masi et al. 2011). The accounts by the online discussants reveal an inward-looking discourse in which social marginalisation is not primarily seen as a structural problem but more as an issue related to personal histories loaded with painful experiences and mental disorders. The stigma of marginalisation might have been hidden inside the inwardlooking discourse in the qualitative data. One way forward could be to consider the different and sometimes hidden ways of speaking about shame (see Scheff 2015, 112-113). 
Finally, when looking at both datasets, the discrepancies in our empirical findings may be related to shortcomings in previous research and particularly their cross-sectional methodological approaches. The assumption tends to be that structural marginalisation precedes financial difficulties and stigma, which eventually cause social marginalisation. For most young adults, the causal relations are probably more complex. The power of these so-called mediating factors between social and structural marginalisation is dependent on the life courses and personal histories of young adults. Financial difficulties probably have the most severe consequences for those structurally marginalised young adults who have been or still are exposed to parental poverty. Moreover, the stigma of structural marginalisation might be only one layer of stigmatised identity consisting of past experiences of being excluded from peer sociability and feeling inferior to other children and young people.

While the modest sample size and non-probability sampling in certain localities are limitations of this study, the benefit of the mixed-methods approach lay in shedding light on different aspects of young adults' lives. In a wider context, as unemployment and dropping out of school have become enduring structural conditions for young adults, it is important to continue to clarify the ways in which structural and social marginalisation are interlinked, particularly from longitudinal perspectives. As previous research has found, the social marginalisation of young adults is a risk factor for their wellbeing, and hence this aspect deserves more rigorous analysis in the future. 


\section{References}

Aaltonen, S., and A. Kivijärvi. 2018. "Disrupting professional practices with research-driven intervention. Researcher-gatekeeper negotiations in the context of targeted youth services." Qualitative Social Work 18 (4): 621-637. https://doi.org/10.1177/1473325018757080

Allan, G. 1998. “Friendship, Sociology and Social Structure.” Journal of Social and Personal Relationships 15 (5): 685-702. doi: 10.1177/0265407598155007

Bergqvist, T. 2016. "The Everyday Life of Young Long-Term Unemployed in Sweden: Coping with Limited Participation and Feelings of Inferiority." In Experiencing Long-Term Unemployment in Europe: Youth on the Edge, edited by C. Lahusen, and M. Giugni, 107-138. London: Palgrave Macmillan UK.

Bynner, J., and S. Parsons. 2002. "Social Exclusion and the Transition from School to Work: The Case of Young People Not in Education, Employment, or Training (NEET)." Journal of Vocational Behavior 60 (2): 289-309. doi: 10.1006/jvbe.2001.1868

Chabanet, D., M. Cinalli, and D. Richard. 2016. "Youth Long-Term Unemployment in France: Challenging Common Trends." In Experiencing Long-Term Unemployment in Europe: Youth on the Edge, edited by C. Lahusen, and M. Giugni, 17-38. London: Palgrave Macmillan UK.

Chambers, D. 2006. New Social Ties: Contemporary Connections in a Fragmented Society. London: Palgrave Macmillan.

Coffey, A. and P. Atkinson. 1996. Making Sense of Qualitative Data. Complementary Research Strategies. London: Sage.

Cotterell, J. 1996. Social Networks and Social Influences in Adolescence. London: Routledge.

Crosnoe, R. 2000. "Friendships in Childhood and Adolescence: The Life Course and New Directions." Social Psychology Quarterly 63 (4): 377-391. doi: 10.2307/2695847

Damelang, A., and G. Kloß. 2013. "Poverty and the Social Participation of Young People - an Analysis of Poverty-Related Withdrawal Mechanisms." Journal for Labour Market Research 46 (4): 321-333. doi: 10.1007/s12651-013-0148-8

Dieckhoff, M., and V. Gash. 2015. "Unemployed and Alone? Unemployment and Social Participation in Europe." The International Journal of Sociology and Social Policy 35 (1/2): 67-90. doi: 10.1108/IJSSP-012014-0002

Emler, N., and S. McNamara. 1996. "The Social Contact Patterns of Young People: Effects of Participation in the Social Institutions of Family, Education and Work." In Youth and Life Management: Research Perspectives, edited by H. Helve, and J. Bynner, 121-139. Helsinki University Press.

Furlong, A., and F. Cartmel. 2007. Young People and Social Change: New Perspectives. McGraw-Hill/Open University Press: Maidenhead, UK.

Gallie, D., S. Paugam, and S. Jacobs. 2003. "Unemployment, Poverty and Social Isolation: Is There a Vicious Circle of Social Exclusion?” European Societies 5 (1): 1-32. doi: 10.1080/1461669032000057668

Goffman, E. 1963. Stigma: Notes on a Spoiled Identity. New Jersey: Prentice-Hall.

Granovetter, M. S. 1977. "The Strength of Weak Ties.” In Social Networks, edited by S. Leinhardt, 347-367. Academic Press.

Gretschel, A. and Myllyniemi, S. 2017. "Työtä, koulutus- tai harjoittelupaikkaa ilman olevien nuorten käsityksiä tulevaisuudesta, demokratiasta ja julkisista palveluista." [Young people not in work, education or apprenticeships and their understanding of the future, democracy and public services]. Nuorisobarometrin erillisnäyte/aineistonkeruu.

Grimmer, B. 2016. "Being Long-Term Unemployed in Germany: Social Contacts, Finances and Stigma.” In Experiencing Long-Term Unemployment in Europe: Youth on the Edge, edited by C. Lahusen, and M. Giugni, 39-72. London: Palgrave Macmillan UK. 
Hall-Lande, J. A., Eisenberg, M. E., Christenson, S. L., \& Neumark-Sztainer, D. 2007. "Social isolation, psychological health, and protective factors in adolescence." Adolescence, 42 (166): 265-286.

Hammer, T. 2003. "Introduction." In Youth Unemployment and Social Exclusion in Europe: A Comparative Study, edited by T. Hammer. Policy Press.

Hammer, T., \& Julkunen, I. (2003). "Surviving unemployment: a question of money or families." Youth Unemployment and Social Exclusion in Europe: A Comparative Study, edited by T. Hammer, 135-154. Policy Press.

Heikkinen, M. 2000. "Social Networks of the Marginal Young: A Study of Young People's Social Exclusion in Finland." Journal of Youth Studies 3 (4): 389-406. doi: 10.1080/713684387

Husu, H.M., and V. Välimäki. 2017. "Staying inside: social withdrawal of the young, Finnish 'Hikikomori'." Journal of Youth Studies 20 (5): 605-621. doi:10.1080/13676261.2016.1254167

Illouz, E. 2008. Saving the Modern Soul: Therapy, Emotions, and the Culture of Self-Help. University of California Press.

Julkunen, I. 2002. "Social and Material Deprivation among Unemployed Youth in Northern Europe." Social Policy \& Administration 36 (3): 235-253. doi: 10.1111/1467-9515.00249

Kieselbach, T. 2003. "Long-Term Unemployment among Young People: The Risk of Social Exclusion." American Journal of Community Psychology 32 (1-2): 69-76. doi: 10.1023/A:1025694823396

Kivijärvi, A. 2014. "Interethnic affiliations and everyday demarcations of youth in Finland: Empirical glances through multisited interviews and observations." Young 22 (1): 67-85.

https://doi.org/10.1177/1103308813512928

Kivijärvi, A., Aaltonen, S., Forma, L., Partanen, J., Myllylä, M., \& Rissanen, P. 2019. "Quality of Life Among Young Finnish Adults not in Employment or Education." Applied Research in Quality of Life. doi:10.1007/s11482-018-9687-z.

Kunze, L., and N. Suppa. 2017. "Bowling Alone or Bowling at All? The Effect of Unemployment on Social Participation." Journal of Economic Behavior \& Organization 133: 213-235. doi:

10.1016/j.jebo.2016.11.012

Lagus, K. and Honkela, T. 2016. "Yksinäisyys mielen rakenteissa." [Loneliness in the structures of the mind]. In Yksinäisten Suomi, edited by J. Saari, 273-295. Helsinki: Gaudeamus.

Lahusen, C., and M. Giugni. 2016. "Experiencing Long-Term Unemployment in Europe: An Introduction." In Experiencing Long-Term Unemployment in Europe: Youth on the Edge, edited by C. Lahusen, and M. Giugni, 1-16. London: Palgrave Macmillan UK.

Levitas, R. 1996. "The Concept of Social Exclusion and the New Durkheimian Hegemony." Critical Social Policy 16 (46): 5-20. doi: 10.1177/026101839601604601

Luhmann, M., and L. C. Hawkley. 2016. "Age Differences in Loneliness from Late Adolescence to Oldest Old Age.” Developmental Psychology 52 (6): 943-959.

MacDonald R., and T. Shildrick. 2007. "Street Corner Society: Leisure Careers, Youth (Sub)culture and Social Exclusion.” Leisure Studies 29 (3): 339-355. doi: 10.1080/02614360600834826

Masi, C. M., Chen, H.-Y., Hawkley, L. C. and Cacioppo, J. T. 2011. "A Meta-analysis of Interventions to Reduce Loneliness.” Personality and Social Psychology Review 15 (3): 219-266.

doi: $10.1177 / 1088868310377394$

Miller, J., L. McAuliffe, N. Riaz, and R. Deuchar. 2015. "Exploring Youths' Perceptions of the Hidden Practice of Youth Work in Increasing Social Capital with Young People Considered NEET in Scotland." Journal of Youth Studies 18 (4): 468-484. doi: 10.1080/13676261.2014.992311

Milner, A., L. Krnjacki, P. Butterworth, and A. D. LaMontagne. 2016. "The Role of Social Support in Protecting Mental Health When Employed and Unemployed: A Longitudinal Fixed-Effects Analysis Using 12 Annual Waves of the HILDA Cohort." Social Science \& Medicine 153: 20-26. doi:

10.1016/j.socscimed.2016.01.050 
Moisio, P., and T. Rämö. 2007. "Koettu yksinäisyys demografisten ja sosioekonomisten taustatekijöiden mukaan Suomessa vuosina 1994 ja 2006." [Experienced loneliness according to demographic and socioeconomic background factors in Finland in 1994 and 2006]. Yhteiskuntapolitiikka 72 (4): 392-401. Helsinki: Stakes.

Monticelli, L., S. Baglioni, and M. Bassoli. 2016. "Youth Long-Term Unemployment and Its Social Consequences in Italy: 'In a World That Does Not Belong to Me."' In Experiencing Long-Term Unemployment in Europe: Youth on the Edge, edited by C. Lahusen, and M. Giugni, 139-169. London: Palgrave Macmillan UK.

Myllyniemi, S. 2012. "Tilasto-osio." ["Quantitative results.”] In Monipolvinen hyvinvointi. Nuorisobarometri 2012 [Intergenerational wellbeing. Youth Barometer 2012], edited by S. Myllyniemi, 13126. Helsinki: Ministry of Education and Culture, Youth Research Society \& State Youth Council.

Myllyniemi S., and T. Kiilakoski. 2017. "Tilasto-osio." ["Quantitative results.”] In Opin polut ja pientareet. Nuorisobarometri 2017 [Roads to learning. Youth Barometer 2017], edited by E. Pekkarinen, and S. Myllyniemi, 9-117. Helsinki: Ministry of Education and Culture, Youth Research Society \& State Youth Council.

Peplau, L. A., and D. Perlman. 1982. "Perspectives on Loneliness." In Loneliness: A Sourcebook of Current Theory, Research and Therapy, edited by L. A. Peplau, and D. Perlman, 1-20. New York: Wiley.

Popp, S., and B. Schels. 2008. “'Do You Feel excluded?' The Subjective Experience of Young State Benefit Recipients in Germany." Journal of Youth Studies 11 (2): 165-191. doi: 10.1080/13676260701851111

Rantakeisu, U., B. Starrin, and C. Hagquist. 1999. "Financial Hardship and Shame: A Tentative Model to Understand the Social and Health Effects of Unemployment." British Journal of Social Work 29 (6): 877 901. doi: 10.1093/bjsw/29.6.877

Russell, D. 1996. "UCLA loneliness scale (version 3): reliability, validity, and factor structure." Journal of Personality Assessment 66 (1): 20-40. doi:10.1207/s15327752jpa6601_2.

Rönkä, A. R. 2017. Experiences of loneliness from childhood to young adulthood. Study of the Northern Finland Birth Cohort 1986. Academic Dissertation, Acta Universitatis Ouluensis, University of Oulu.

Scheff, T. 2015. Toward defining basic emotions. Qualitative Inquiry, 21(2), 111-121.

Silva, J. M. 2012. "Constructing Adulthood in an Age of Uncertainty." American Sociological Review 77 (4): 505-522. doi: 10.1177/0003122412449014

Silva, J. M. 2013. Coming up Short: Working-Class Adulthood in an Age of Uncertainty. Oxford University Press.

Weiss, R. S. 1973. Loneliness: the experience of emotional and social isolation. Cambridge, MA: The MIT Press. 
Table 1. Description of the respondents $(n=147)$

\begin{tabular}{lcc}
\hline Gender & $\mathrm{n}$ & $\%$ \\
Men & 66 & 45.2 \\
Women & 74 & 50.0 \\
Other/did not say & 7 & 4.8 \\
Age & & \\
16-20 & 35 & 23.8 \\
$21-25$ & 75 & 51.0 \\
$25-30$ & 36 & 24.5 \\
Missing & 1 & 0.7 \\
Education & & \\
Comprehensive school & 56 & 38.6 \\
Secondary education & 82 & 55.7 \\
Tertiary & 7 & 4.7 \\
Missing & 2 & 1.4 \\
Household unit & & \\
Marriage or cohabiting & 23 & 15,6 \\
One-person household & 74 & 50,3 \\
Living with parents & 32 & 21,8 \\
Missing & 18 & 12,2 \\
& & \\
\hline
\end{tabular}


Table 2: Determinants of loneliness in the baseline survey $(n=147)$, linear regression models

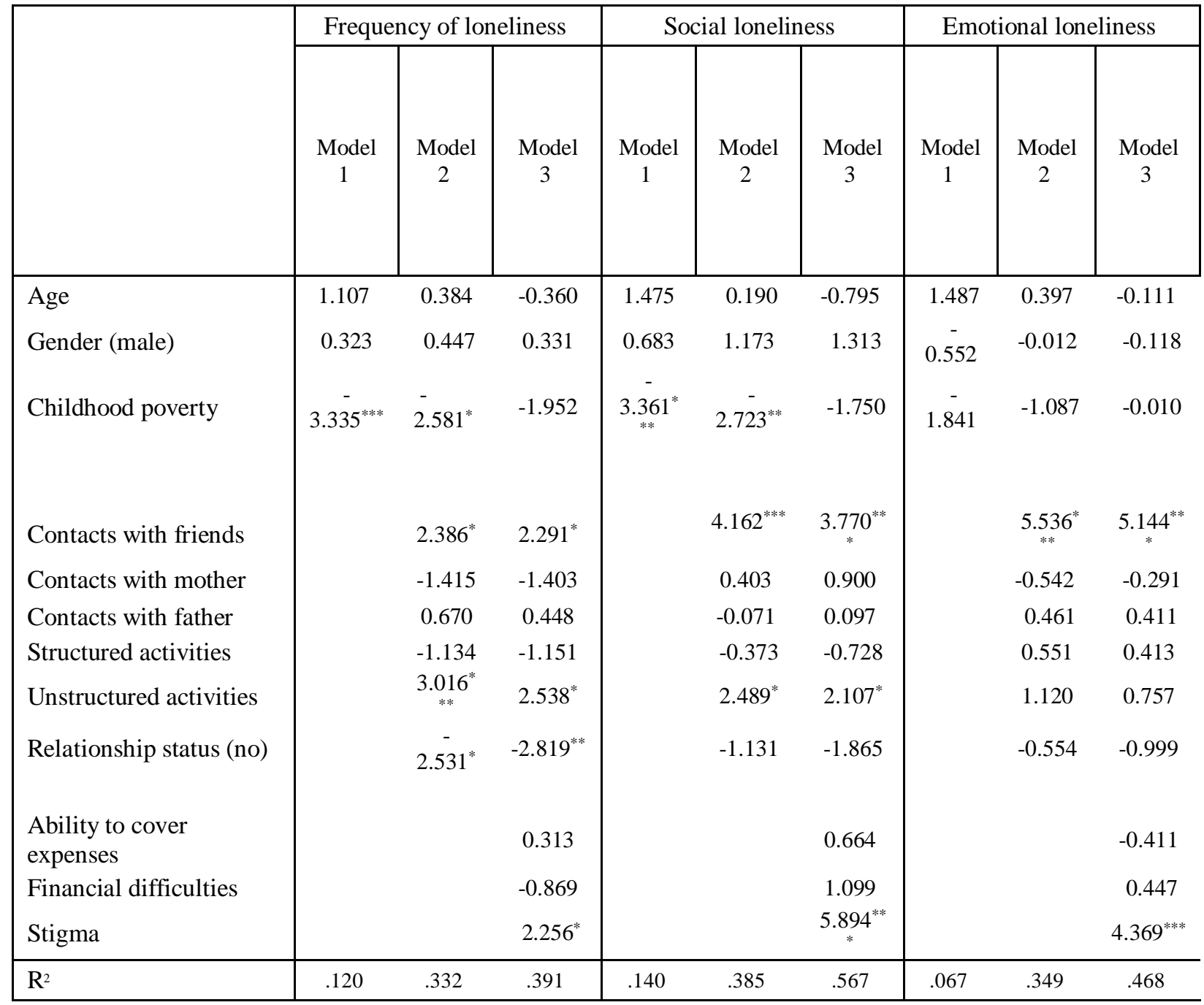

\footnotetext{
$* \mathrm{p} \leq .005$

$* * \mathrm{p} \leq .010$

$* * * \mathrm{p} \leq .050$
} 
Table 3. Predictors of change in the levels of loneliness between baseline and follow-up surveys $(\mathrm{n}=107)$, linear regression models

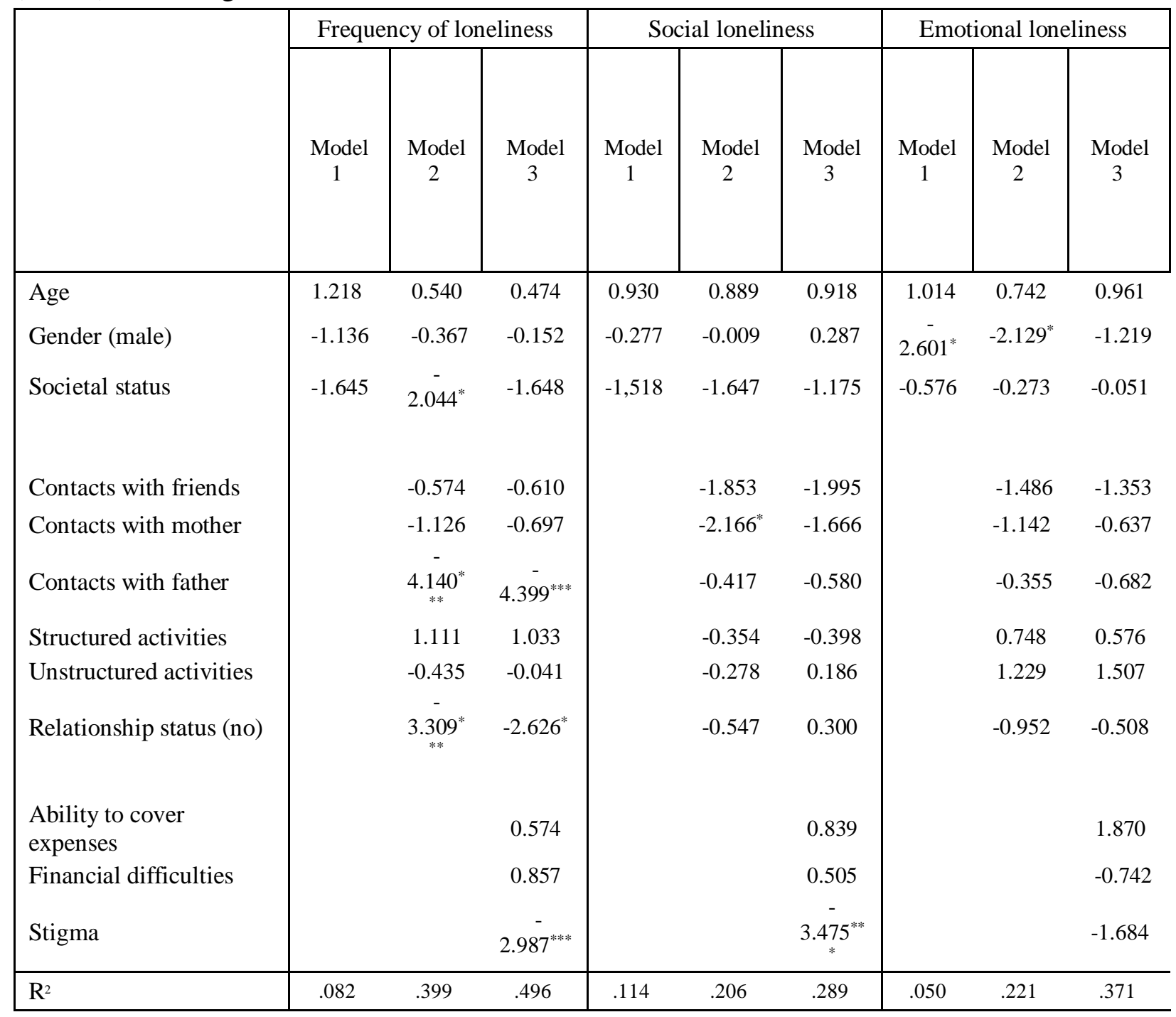

\footnotetext{
$* \mathrm{p} \leq .005$

$* * \mathrm{p} \leq .010$

$* * * \mathrm{p} \leq .050$
} 